\title{
Cryptotanshinone from the Salvia miltiorrhiza Bunge Attenuates Ethanol-Induced Liver Injury by Activation of AMPK/SIRT1 and Nrf2 Signaling Pathways
}

\author{
Arulkumar Nagappan 1,2, Ji-Hyun Kim ${ }^{1,2}$, Dae Young Jung 1,2 and Myeong Ho Jung 1,2,* \\ 1 Healthy Aging Korean Medical Research Center, School of Korean Medicine, Pusan National University, \\ Yangsan 50612, Korea; arulbiotechtnau@gmail.com (A.N.); kimji77@pusan.ac.kr (J.-H.K.); \\ dyjung999@naver.com (D.Y.J.) \\ 2 Division of Longevity and Biofunctional Medicine, School of Korean Medicine, Pusan National University, \\ Yangsan 50612, Korea \\ * Correspondence: jung0603@pusan.ac.kr; Tel.: +82-51-510-8468
}

Received: 9 December 2019; Accepted: 27 December 2019; Published: 30 December 2019

check for updates

\begin{abstract}
Cryptotanshinone (CT), a diterpene that is isolated from Salvia miltiorrhiza Bunge, exhibits anti-cancer, anti-oxidative, anti-fibrosis, and anti-inflammatory properties. Here, we examined whether $\mathrm{CT}$ administration possess a hepatoprotective effect on chronic ethanol-induced liver injury. We established a chronic alcohol feeding mouse model while using C57BL/6 mice, and examined the liver sections with hematoxylin-eosin (H\&E) and Oil Red O (ORO) staining. Further, we analyzed the lipogenesis, fatty acid oxidation, oxidative stress, and inflammation genes by using quantitative polymerase chain reaction (qPCR) and immunoblotting in in vivo, and in vitro while using HepG2 and AML-12 cells. CT treatment significantly ameliorated ethanol-promoted hepatic steatosis, which was consistent with the decreased hepatic triglyceride levels. Interestingly, CT activated the phosphorylation of AMP-activated protein kinase (AMPK), sirtuin 1 (SIRT1), and nuclear factor E2-related factor 2 (Nrf2) proteins. Importantly, compound C ( $A M P K$ inhibitor) significantly blocked the CT-mediated reduction in TG accumulation, but not Ex52735 (SIRT1 inhibitor), which suggested that $\mathrm{CT}$ countering ethanol-promoted hepatic steatosis is mediated by AMPK activation. Furthermore, CT significantly inhibited cytochrome P450 2E1 (CYP2E1) and enhanced both the expression of antioxidant genes and hepatic glutathione levels. Finally, CT inhibited the ethanol-induced inflammation in ethanol-fed mice and HepG2 cells. Overall, CT exhibits a hepatoprotective effect against ethanol-induced liver injury by the inhibition of lipogenesis, oxidative stress, and inflammation through the activation of AMPK/SIRT1 and Nrf2 and the inhibition of CYP2E1. Therefore, CT could be an effective therapeutic agent for treating ethanol-induced liver injury.
\end{abstract}

Keywords: cryptotanshinone; AMP-activated protein kinase; nuclear factor E2-related factor 2; alcohol liver disease; cytochrome P450 2E1; sirtuin 1

\section{Introduction}

The dried roots of Salvia miltiorrhiza Bunge, called Danshen, has been used in Chinese folk medicine for over a thousand years to treat various disorders, including heart disease, liver diseases, haematological abnormalities, cerebrovascular disease, haemorrhage, menstrual disorders, miscarriage, as well as oedema and insomnia [1-4]. Recent studies have demonstrated that S. miltiorrhiza ameliorates carbon tetrachloride $\left(\mathrm{CCl}_{4}\right)$-induced liver fibrosis in vivo and in vitro [5]. Tanshinone IIA, dihydrotanshinone I, tanshinone I, and cryptotanshinone are the major abietane diterpene isolates 
from the root of S. miltiorrhiza all of which are potent antioxidants that suppress lipid peroxidation and remedy for various metabolic disorders [6,7]. Among these, cryptotanshinone (CT) is reported to have various biological functions, such as anti-cancer, anti-inflammatory, and anti-oxidative activities [8,9]. Specifically, CT was able to effectively inhibit lipopolysaccharide (LPS)-triggered Toll-like receptor 4 (TLR4) signaling and nuclear factor-kappa $\mathrm{B}(N F-\kappa B)$ downstream pathways in murine macrophage RAW 264.7 [8]. In addition, CT ameliorates ethanol-induced hepatotoxicity by blocking hepatic cell death and fatty acid synthesis in primary rat hepatocytes [10]. However, the protective effects of CT against alcohol-induced fatty liver, and the exact underlying molecular mechanisms have not yet been reported. Hence, studying the protective effect of CT against alcoholic liver disease (ALD) might uncover the precise protective mechanism and provide a therapeutic potential for ALD treatment.

Alcoholism leads to alcoholic liver disease (ALD), which is a major cause of alcohol-related morbidity worldwide [11]. According to the WHO, alcohol consumption caused more than three-million deaths worldwide in 2016. The mortality rate due to alcohol abuse is higher than that of tuberculosis, HIV/AIDS, and diabetes. Fatty liver formation is an early stage of the ALD, which can evolve into advanced conditions, such as steatohepatitis, cirrhosis, fibrosis, and hepatocarcinoma [12-14]. There are multiple mechanisms that are associated with alcoholic fatty liver, including augmentation of lipogenesis, lipid peroxidation, oxidative stress, and the inhibition of fatty acid oxidation [12,15]. Thus, the inhibition of triglycerides (TG) and regulation of lipid metabolism could be a feasible remedy for ALD in terms of clinical outcomes and economic feasibility.

The AMP-activated protein kinase (AMPK) is the main sensor of cellular energy status [16], and it plays a crucial role in glucose and lipid metabolism [17]. Many studies suggest that the activation of $A M P K$ could increase fatty acid oxidation and decrease lipogenesis [15,18-20]. AMPK can also activate sirtuin 1 (SIRT1), a nicotinamide adenosine dinucleotide (NAD)-dependent deacetylase, by increasing the substrate for SIRT1 activity that is NAD+ levels [21], and SIRT1 can stimulate AMPK via the modulation of upstream $A M P K$ kinase, liver kinase B1 [22]. Recent studies demonstrated that AMPK/SIRT1 activation could protect ethanol-promoted liver diseases [22-24]. Our previous study also demonstrated that Gomisin N activates AMPK in ethanol-induced fatty liver in vivo and in vitro [25]. Therefore, the $A M P K$ pathway and its downstream target genes have gained attention as potential targets for liver protection.

There is ample evidence suggesting that oxidative stress and lipid peroxidation also play a crucial role in the pathogenesis of ALD [12,26-28]. Alcohol exposure increases the activity of cytochrome P450 2E1 (CYP2E1), a major contributor to reactive oxygen species (ROS) generation, which is also involved in the development of fatty liver [29-31]. The inhibition of CYP2E1 activity has been shown to result in successful recovery of ethanol-induced fatty liver [32]. Nuclear factor E2-related factor 2 (Nrf2) is another important regulator of the intracellular adaptive antioxidant response to oxidative stress [33-35]. In addition, alcohol exposure is shown to induce hepatic lipid accumulation in Nrf2-null mice [36], and the activation of $N r f 2$ was able to successfully prevent alcohol-induced fatty liver [37]. Moreover, SIRT1 can regulate transcription factors, such as Nrf2 and NF- $\kappa B$, which are involved in the regulation of antioxidant genes in the face of oxidative damage and suppression of pro-inflammatory cytokines, respectively [38-42]. Therefore, the amelioration of oxidative stress by the activation of antioxidant genes and regulation of inflammatory genes could be another effective mode of action against ethanol-induced liver injury.

Based on the evidence from above studies, we investigated whether CT has a protective effect against alcohol-induced hepatotoxicity while using a chronic-ethanol-drinking model in mice in vivo and in vitro using HepG2 and AML-12 cells. We examined the effects of CT on the de novo lipogenesis, fatty acid oxidation, oxidative stress and inflammation, and measured AMPK/SIRT1 signaling to elucidate the underlying mechanism of the protective effect of CT against ethanol-induced liver injury. To our knowledge, this is first study elucidating the mechanism underlying the hepatoprotective effects of $\mathrm{CT}$ against ethanol-induced fatty liver. 


\section{Results}

\subsection{CT Countered Ethanol-Promoted Hepatic Steatosis in Chronic Ethanol-Fed Mice}

It is well known that ethanol exposure induces hepatic steatosis [12]. We established a chronic alcohol feeding mouse model while using C57BL/6 mice to evaluate the effects of CT on ethanol-promoted hepatic steatosis. Hence, the mice were randomly divided into the four groups ( $\mathrm{n}=10 /$ group): control, ethanol, ethanol + CT $20 \mathrm{mg} / \mathrm{kg}$, and ethanol + CT $40 \mathrm{mg} / \mathrm{kg}$. During the experiments for four weeks, ethanol feeding led to body weight loss. CT administration did not affect body weight changes in ethanol feeding mice group (Supplementary Figure S1A). After four weeks of treatment, the liver index in ethanol-fed group $(4.477 \pm 0.113 \%)$ was higher than that in the control group $(4.353 \pm 0.241 \%)$, and it was significantly decreased by CT treatment at both low dose $(20 \mathrm{mg} / \mathrm{kg})(4.255 \pm 0.129 \%)$ and high dose $(40 \mathrm{mg} / \mathrm{kg})(4.085 \pm 0.164 \%)$ (Figure $1 \mathrm{~A})$. In addition, white-colored fatty livers were observed in ethanol-fed mice, whereas the CT-treated groups had healthy livers (Figure 1B, upper). Liver sections of the chronic ethanol exposure group that were stained with with haematoxylin and eosin (H\&E) showed fat deposits, and Oil Red O (ORO) staining revealed the accumulation of lipid droplets (Figure 1B, middle and bottom). The NAFLD activity score (NAS) for H\&E staining is given in Supplementary Figure S1B. However, CT treatment was able to significantly decrease the ethanol-induced hepatic fat deposition. In addition, ethanol-induced hepatic TG accumulation was significantly suppressed by CT administration (Figure 1C), consistent with the results of H\&E and ORO staining. Serum biochemistry showed that the TG levels were elevated in the chronic ethanol-fed group, and the elevated TG levels were effectively decreased by CT treatment (Figure 1D). The aspartate aminotransferase (AST) levels were not only induced by ethanol consumption, but CT administration significantly reduced the AST levels as compared to only ethanol-treated group (Figure 1E). Meanwhile, alanine aminotransferase (ALT) levels were also not induced in only the ethanol-fed group, but CT administration tended to decrease ALT levels when compared to only ethanol-treated group (Supplementary Figure S1C). Also, ADH1 mRNA increased in mice treated with ethanol only and in mice treated with ethanol plus CT (Supplementary Figure S1D); however, ALDH2 expression also significantly increased in the CT treatment groups (Supplementary Figure S1E). These findings suggest that oxidation of ethanol to acetaldehyde and ALDH2 overexpression may detoxify acetaldehyde in the liver of CT-treated mice. Altogether, ethanol promoted hepatic steatosis with liver injury, which was ameliorated by CT treatment in chronic ethanol-fed mice. 


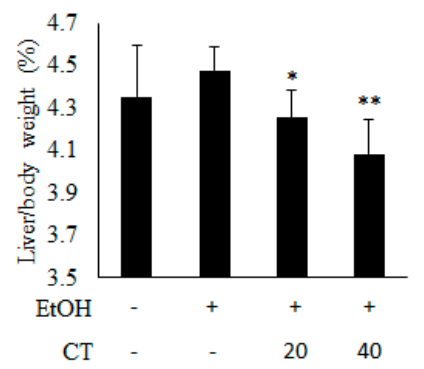

C)

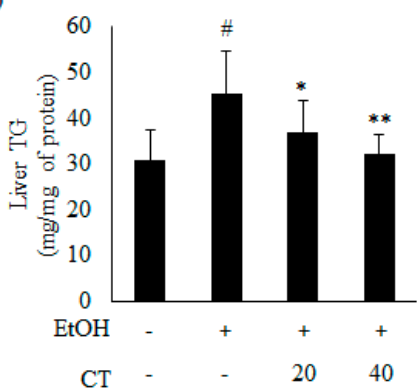

B)

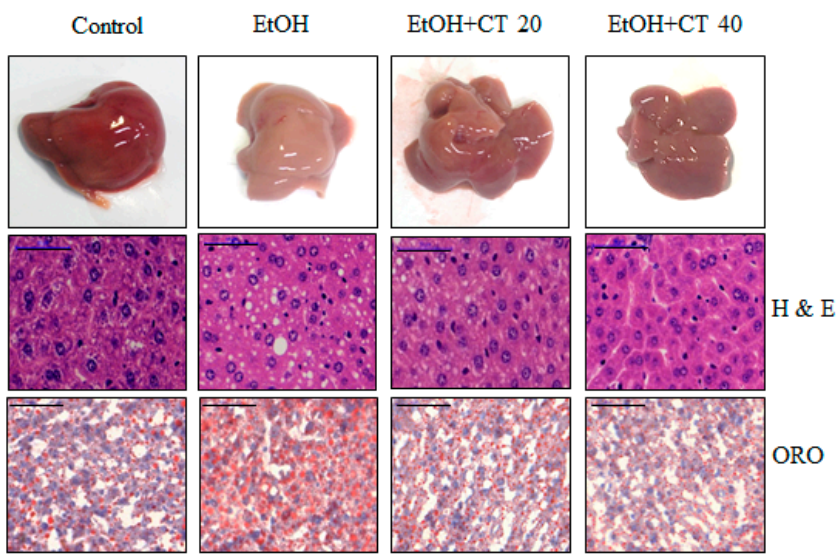

D)

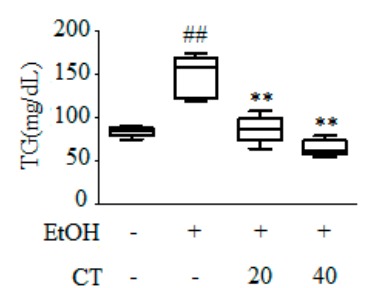

E)

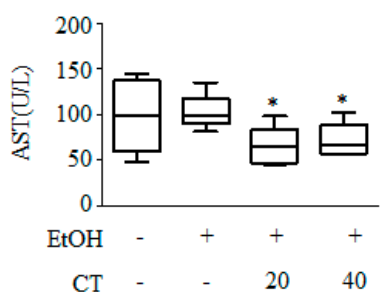

Figure 1. Cryptotanshinone (CT) countered ethanol-promoted hepatic steatosis in chronic ethanol-fed mice. C57BL/6 mice were given feeding control or ethanol-containing diet with or without CT (20 or $40 \mathrm{mg} / \mathrm{kg}$ ) for four weeks. (A) Liver body index (\%). (B) Liver morphology (upper), hematoxylin and eosin (H\&E) staining (middle), and Oil Red O (ORO) staining (bottom) (scale bar $=50 \mu \mathrm{m}$ ). The images shown are representative of H\&E and ORO staining. NAFLD activity score (NAS) for H\&E staining is given in Supplementary Figure S1B. (C) Triglyceride (TG) levels of liver respective groups. (D) Serum levels of TG. (E) Serum levels of AST. Data are shown as mean $\pm \mathrm{SD}(\mathrm{n}=6) .{ }^{*} p<0.05$, \#\# $p<0.01$ vs. pair-fed control mice, ${ }^{*} p<0.05,{ }^{* *} p<0.01$ vs. ethanol-fed mice.

2.2. CT Mitigates Ethanol-Induced TG Accumulation by Regulating Lipogenesis and Fatty Acid Oxidation in Chronic Ethanol-Fed Mice and HepG2 Cells

We evaluated the inhibitory effects of CT on intracellular TG accumulation in ethanol-treated HepG2 and AML12 cells to confirm the in vivo protective effect of CT against hepatic steatosis. First, we examined the cytotoxicity of only CT or ethanol, and that of a combination of CT and ethanol to HepG2 and AML-12 cells. Both cell types were treated with $50 \mathrm{mM}$ ethanol in the presence or absence of CT $(2.5,5.0$, or $10 \mu \mathrm{M})$ for $24 \mathrm{~h}$ and 3-(4,5- dimethylthiazol-2-yl)-2,5-diphenyltetrazolium bromide (MTT) assay was performed. CT treatment produced no inhibitory effects on the viability of both cell types (Figure 2A,D) and a combination of 2.5 or $5.0 \mu \mathrm{M} \mathrm{CT}$ and $50 \mathrm{mM}$ ethanol exhibited no cytotoxicity in both cell types (Figure 2B,E). Therefore, the co-treatment of both cell types with $\mathrm{CT}$ and ethanol was performed while using 2.5 or $5.0 \mu \mathrm{M} \mathrm{CT}$ and $50 \mathrm{mM}$ ethanol in subsequent experiments. Subsequently, we assessed the potential inhibitory effects of CT on intracellular TG accumulation in ethanol-treated cells. As shown in Figure 2C,F, CT treatment significantly inhibited the ethanol-induced intracellular TG accumulation in both cell types. These findings suggest that CT can inhibit ethanol-stimulated intracellular TG accumulation in HepG2 and AML-12 cells. 

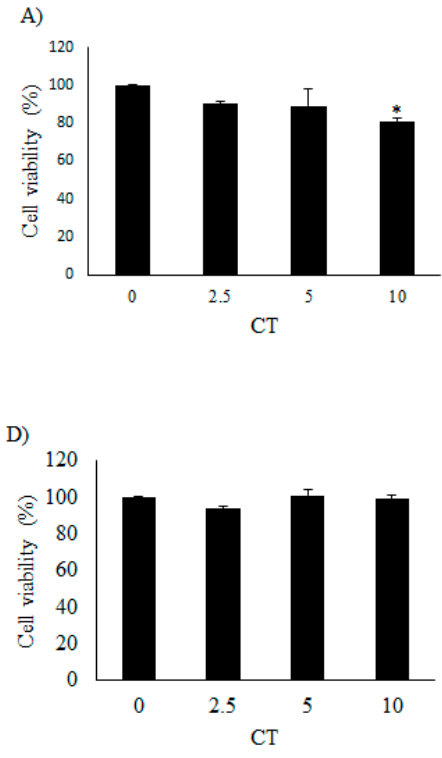

HepG2 cells

B)

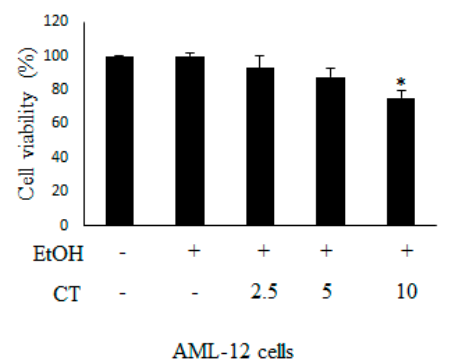

E)

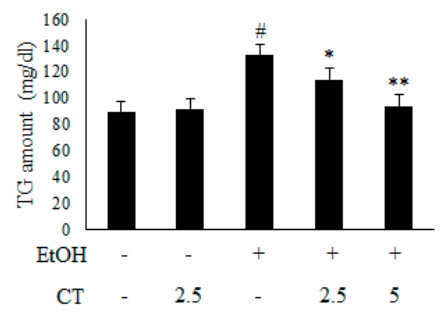

F)
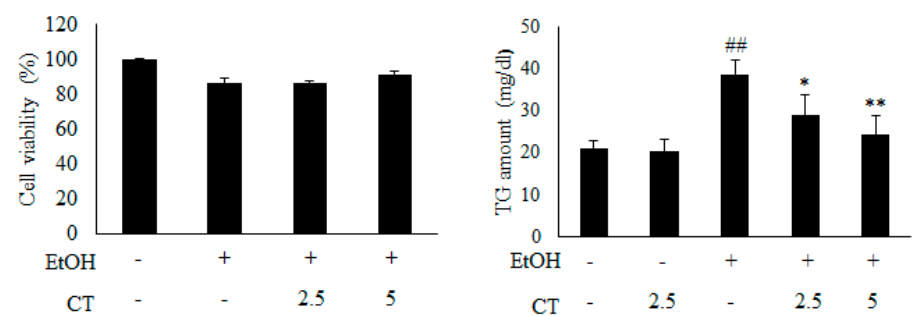

Figure 2. $\mathrm{CT}$ attenuated ethanol-induced intracellular TG accumulation in HepG2 and AML-12 cells. (A,B,D,E) HepG2 and AML-12 cells were treated with only CT at indicated concentrations and combined with $50 \mathrm{mM}$ ethanol for $24 \mathrm{~h}$. Cell viability was assessed by 3-(4,5dimethylthiazol-2-yl)-2,5-diphenyltetrazolium bromide (MTT) assay. (C,F) HepG2 and AML-12 cells were treated with $50 \mathrm{mM}$ ethanol in the presence or absence of $\mathrm{CT}(2.5$ or $5 \mu \mathrm{M})$ for $24 \mathrm{~h}$. Measurement of intracellular TG levels in HepG2 and AML-12 cells. Values are mean \pm SD from triplicate experiments. ${ }^{\#} p<0.05,{ }^{\# \#} p<0.01$ vs. untreated control, ${ }^{*} p<0.05,{ }^{* *} p<0.01$ vs. ethanol-treated group.

Alcohol exposure enhances lipogenesis and impairs fatty acid oxidation, which leads to the development of hepatic steatosis [12,43]. Hence, we investigated the expression of lipogenesis- and fatty acid oxidation-related genes in the liver of ethanol-fed mice and HepG2 cells, with or without CT treatment. The expression of sterol regulatory element-binding protein-1c (SREBP-1c) at mRNA and protein levels, which is a key transcription factor that regulates lipogenesis and its downstream lipogenesis genes, including fatty acid synthase (FAS) and stearoyl-CoA desaturase-1 (SCD1), were increased in ethanol-fed mice and ethanol-treated HepG2 cells, but CT treatment was able to reduce the expression of lipogenesis-related genes (Figure 3A,B). Moreover, the expressions fatty acid oxidation genes, such as peroxisome proliferator-activated receptor $\alpha(P P A R \alpha)$, carnitine palmitoyltransferase- $1 \alpha$ $(C P T 1)$, and acyl-coenzyme A oxidase $(A C O)$, were significantly reduced in ethanol-fed mice and HepG2 cells, and CT administration significantly reversed these ethanol-induced effects (Figure 4A,B). These results suggest that $\mathrm{CT}$ could ameliorate ethanol-induced steatosis by decreasing lipogenesis and increasing fatty acid oxidation in chronic ethanol-fed mice and HepG2 cells. 
A)

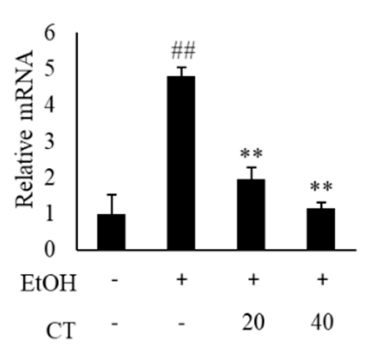

mFAS

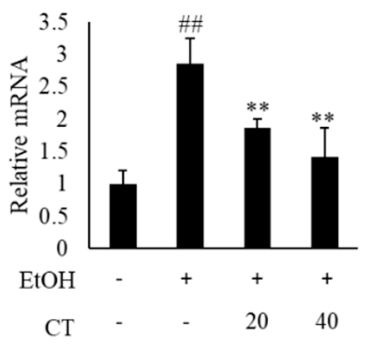

mSCD1

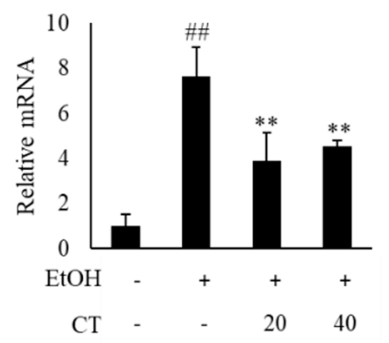

B)
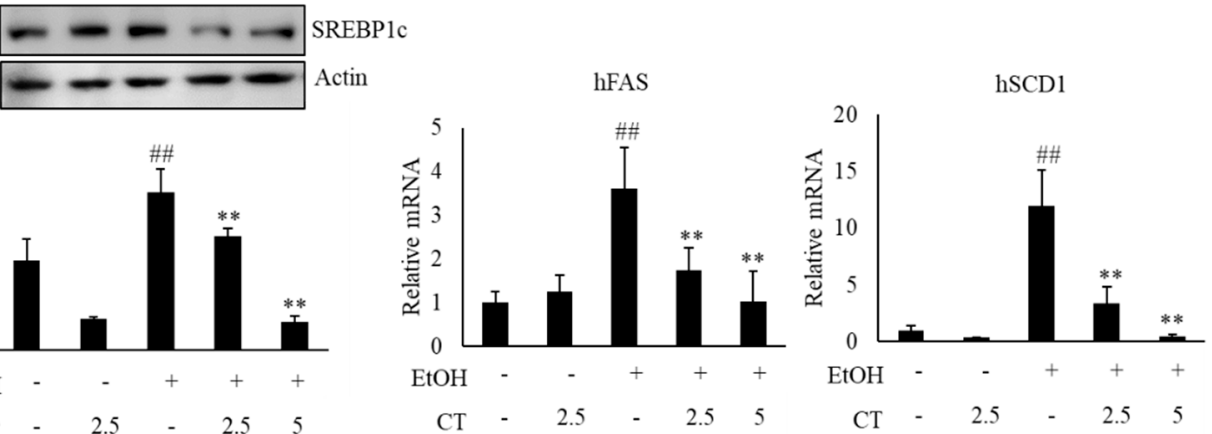

Figure 3. CT decreased the lipogenesis genes in ethanol-fed mice and HepG2 cells. (A) C57BL/6 mice were pair-fed either control or ethanol-containing diet with or without CT (20 or $40 \mathrm{mg} / \mathrm{kg}$ ) for 4 weeks. qPCR analysis of $\mathrm{mSREBP}-1 c, \mathrm{~m} F A S$, and $\mathrm{mSCD} 1$. Data are shown mean $\pm \mathrm{SD}(n=6) .{ }^{*} p<0.05$, \#\# $p<0.01$ vs. pair-fed control mice, ${ }^{*} p<0.05,{ }^{* *} p<0.01$ vs. ethanol-fed mice. (B) HepG2 cells were incubated with $50 \mathrm{mM}$ ethanol and treated with CT $(2.5$ or $5 \mu \mathrm{M})$ for $24 \mathrm{~h}$. Western blot and qPCR analysis of $\mathrm{hSREBP}-1$ and $\mathrm{qPCR}$ analysis of $\mathrm{hFAS}$, and $\mathrm{hSCD1}$. Values are mean $\pm \mathrm{SD}$ from triplicate experiments ${ }^{\# \#} p<0.01$ vs. untreated control, ${ }^{* *} p<0.01$ vs. ethanol-treated group.

A)

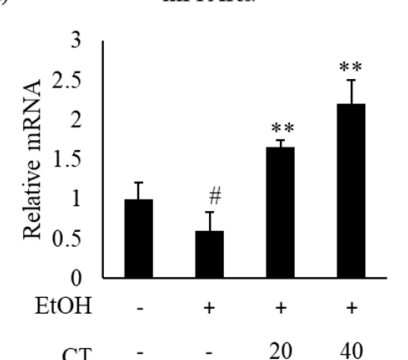

B)

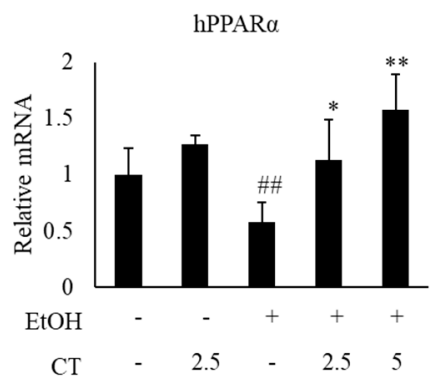

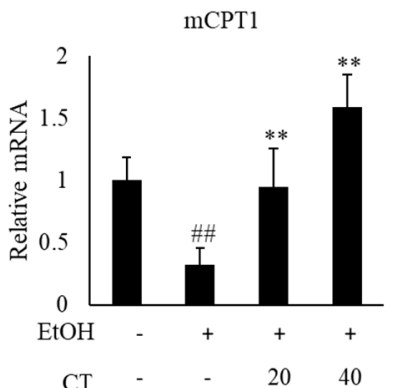

hCPT1
$\mathrm{mACO}$

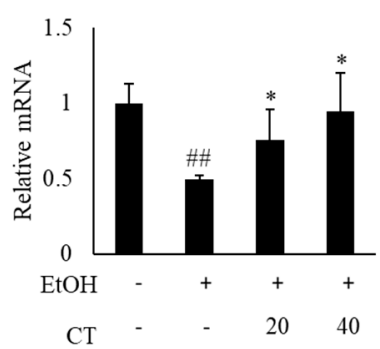

$\mathrm{hACO}$

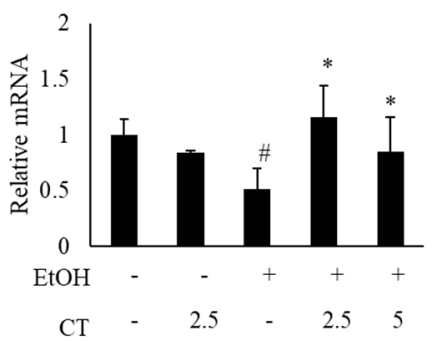

Figure 4. CT stimulated fatty acid oxidation in ethanol-fed mice and HepG2 cells. (A) C57BL/6 mice were pair-fed either control or ethanol-containing diet with or without CT (20 or $40 \mathrm{mg} / \mathrm{kg}$ ) for 4 weeks. qPCR analysis of $\mathrm{mPPAR} \alpha, \mathrm{mCPT1}$, and $\mathrm{mACO}$. Data are shown mean $\pm \mathrm{SD}(n=6) .{ }^{*} p<0.05,{ }^{\# \#} p<0.01$ vs. pair-fed control mice, ${ }^{*} p<0.05,{ }^{* *} p<0.01$ vs. ethanol-fed mice. (B) The HepG2 cells were incubated with $50 \mathrm{mM}$ ethanol and treated with CT $(2.5$ or $5 \mu \mathrm{M})$ for $24 \mathrm{~h}$. qPCR analysis of hPPAR $\alpha, \mathrm{hCPT1}$, and $\mathrm{h} A C O$. Values are mean $\pm \mathrm{SD}$ from triplicate experiments. ${ }^{\#} p<0.05,{ }^{\#} p<0.01$ vs. untreated control, ${ }^{*} p<0.05,{ }^{* *} p<0.01$ vs. ethanol-treated group. 


\subsection{CT Activated AMPK/SIRT1 Signaling in Ethanol-Treated Mice and HepG2 Cells}

AMPK/SIRT1 activation is a potential therapeutic target against ALD [22-24]. We evaluated the levels of phosphorylated AMPK and SIRT1 protein in CT-treated HepG2 and AML-12 cells to decipher the underlying mechanisms involved in the protective effects of $\mathrm{CT}$ against ethanol-induced ALD. The levels of phosphorylated AMPK and ACC, a target of AMPK downstream, were increased by $\mathrm{CT}$ treatment after $3 \mathrm{~h}$ treatment, and the SIRT1 protein was also increased by CT treatment after $6 \mathrm{~h}$ and $12 \mathrm{~h}$ treatment in HepG2 cells (Figure 5A,B). Subsequently, we further assessed the levels of phosphorylated AMPK and SIRT1 in the liver of ethanol-fed mice and, HepG2 and AML-12 cells. Ethanol exposure exhibited the reduced levels of phosphorylated AMPK, and SIRT1 protein in the liver of ethanol-fed mice (Figure 5C), and HepG2 (Figure 5D) and AML-12 cells (Figure 5E) as compared with control groups; however, $\mathrm{CT}$ administration efficiently restored them. HepG2 cells were pretreated with CT and/or compound C (AMPK Inhibitor) and Ex52735 (SIRT1 inhibitor) before treatment with ethanol and TG accumulation was evaluated to further examine the role of AMPK/SIRT1 in CT-mediated protection against ethanol-induced hepatic steatosis. As shown in Figure 5F, CT treatment significantly suppressed the ethanol-stimulated intracellular TG accumulation in HepG2 cells. However, co-treatment with compound C significantly blocked the CT-mediated reduction in TG accumulation, but not Ex52735 (Supplementary Figure S3H), which suggested that $A M P K$ activation mediates CT countering ethanol-promoted hepatic steatosis. In addition, the stimulatory effects of CT on AMPK/SIRT1 were also proven in AML-12 cells. As shown in Figure 5F, $\mathrm{CT}$ increased the levels of $\mathrm{p}-A M P K$ and SIRT1, and recovered ethanol-mediated reduction in those levels (Figure 5F). Collectively, these results demonstrated that CT stimulated hepatic AMPK/SIRT1 signaling, which might act as defense mechanism of CT against ALD.
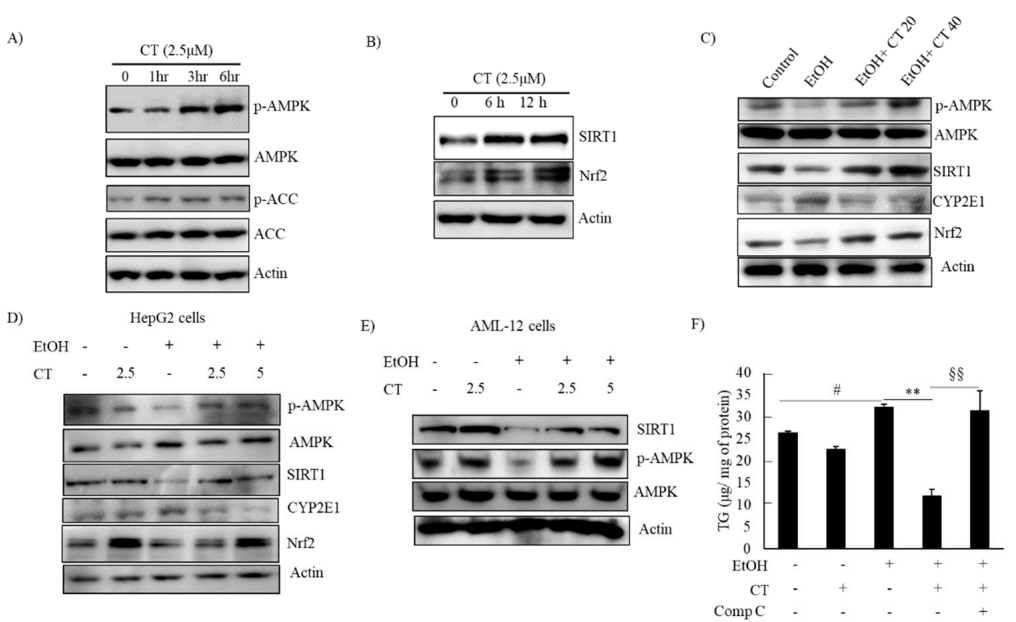

Figure 5. CT activated AMPK/SIRT1 signaling. (A,B) HepG2 cells were treated with $2.5 \mu \mathrm{M}$ CT for indicated times. Western blot analysis of phosphorylated AMPK, ACC, SIRT1, and Nrf2. (C) C57BL/6 mice were pair-fed either control or ethanol-containing diet with or without CT (20 or $40 \mathrm{mg} / \mathrm{kg}$ ) for four weeks. Western blot analysis of phosphorylated AMPK, SIRT1. CYP2E1, and Nrf2. (D) HepG2 cells were incubated with $50 \mathrm{mM}$ ethanol and treated with CT $(2.5$ or $5 \mu \mathrm{M})$ for $24 \mathrm{~h}$. Western blot analysis of phosphorylated AMPK, SIRT1, CYP2E1, and Nrf2. (E) AML-12 cells were incubated with $50 \mathrm{mM}$ ethanol and treated with CT $(2.5$ or $5 \mu \mathrm{M})$ for $24 \mathrm{~h}$. Western blot analysis of phosphorylated $A M P K$ and SIRT1. The images are representative $(\mathrm{F}) \mathrm{HepG} 2$ cells were pretreated with CT $(2.5 \mu \mathrm{M})$ for $3 \mathrm{~h}$ or with compound C (comp C) $(10 \mu \mathrm{M})$ for $6 \mathrm{~h}$, followed by ethanol $(100 \mu \mathrm{M})$ treatment. Measurement of intracellular TG levels. Data are shown as mean \pm SD of three independent experiments. ${ }^{*} p<0.05$ vs. untreated control, ${ }^{* *} p<0.01$ vs. ethanol-treated group. $\$ \S p<0.01$ vs. ethanol and CT-treated group. Densitometric analysis of western blots are given in Supplementary Figures S2 and S3A-G. 


\subsection{CT Prevents Ethanol-Induced Oxidative Stress in Chronic Ethanol-Fed Mice and HepG2 Cells}

Previous studies suggest that oxidative stress and inflammation also play a crucial role in the pathogenesis of ALD [12]. Hence, we examined the effects of CT on oxidative stress and inflammation genes in the liver of ethanol-fed mice and HepG2 cells. First, we determined the hepatic TBARS levels (measured as malondialdehyde MDA, an indicator of lipid peroxidation) to evaluate the oxidative damage. The results showed that hepatic TBARS levels were significantly increased in the ethanol-fed mice, but CT administration significantly reduced the TBARS levels (Figure 6A). This result suggested that CT protected the mice against ethanol-induced oxidative stress.

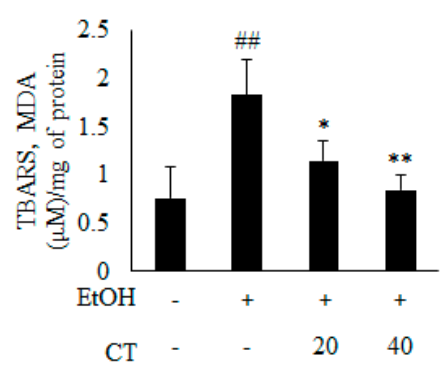

C)

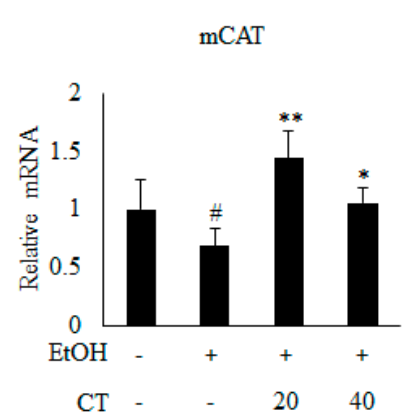

B)

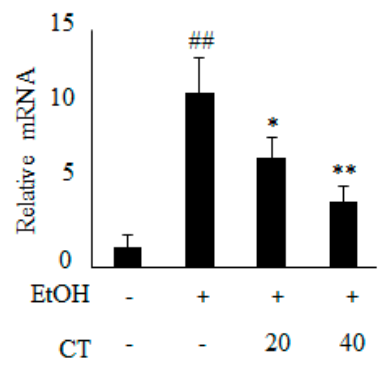

$\mathrm{mSOD}$

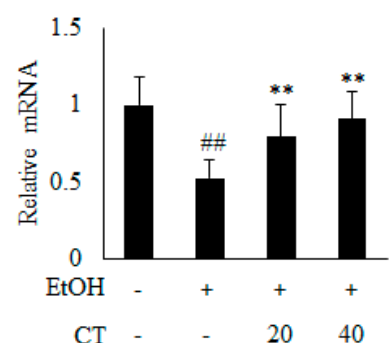

D)

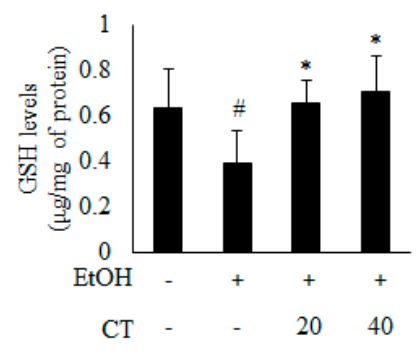

mGPX

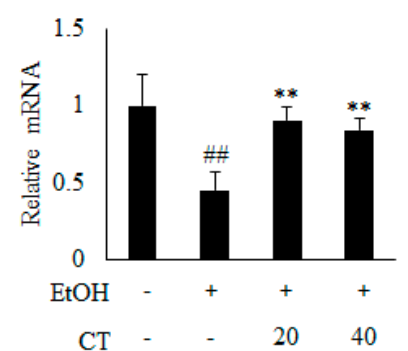

Figure 6. CT attenuated ethanol-induced oxidative stress in chronic ethanol-fed mice. C57BL/6 mice were pair-fed either control or ethanol-containing diet with or without CT (20 or $40 \mathrm{mg} / \mathrm{kg}$ ) for four weeks. (A) TBARS levels of respective groups. (B) qPCR analysis of CYP2E1. (C) qPCR analysis of $\mathrm{mCAT}, \mathrm{mSOD}$, and $\mathrm{mGPX}$. (D) Hepatic levels of glutathione (GSH). Data are expressed as mean $\pm \mathrm{SD}$ $(n=6) .{ }^{\#} p<0.05,{ }^{\# \#} p<0.01$ vs. pair-fed control mice, ${ }^{*} p<0.05,{ }^{* *} p<0.01$ vs. ethanol-fed mice.

It has been reported that CYP2E1 plays a critical role in ethanol-induced ROS generation [31]. Thus, we examined whether CYP2E1 inhibition and improvement of the antioxidant defense system mediated the protective effect of $\mathrm{CT}$ against oxidative stress. The results revealed that the protein and the mRNA levels of CYP2E1 increased upon ethanol consumption in ethanol fed mice.

Which was significantly reduced by CT treatment (Figures 5C and 6B). Moreover, ethanol exposure significantly reduced the antioxidant genes, such as catalase (CAT), superoxide dismutase (SOD), and glutathione peroxidase (GPX) (Figure 6C) and hepatic glutathione (GSH) levels (Figure 6D), while CT treatment significantly reversed these ethanol-mediated effects. The in vivo inhibitory effects of CT on oxidative stress was also examined in HepG2 cells. Ethanol treatment increased the protein and mRNA levels of CYP2E1 in HepG2 cells (Figures 5D and 7A); however, CT prevented the increase. Furthermore, ethanol treatment reduced both GSH levels (Figure 7B) and the antioxidant genes including CAT, SOD, and GPX at mRNA levels (Figure 7C), but CT treatment prevented the ethanol-mediated reduction in HepG2 cells. Taken together, our results suggest that CT prevents ethanol-induced oxidative stress in ethanol-fed mice and HepG2 cells. 
A)

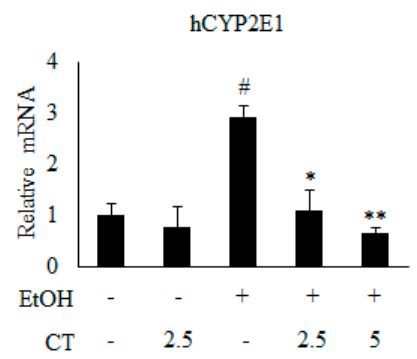

B)

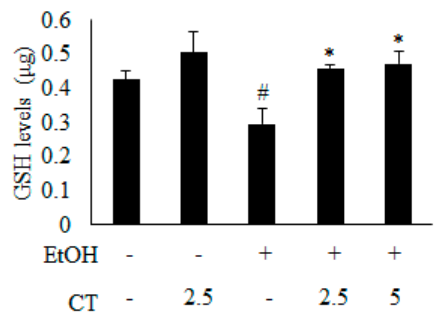

C)
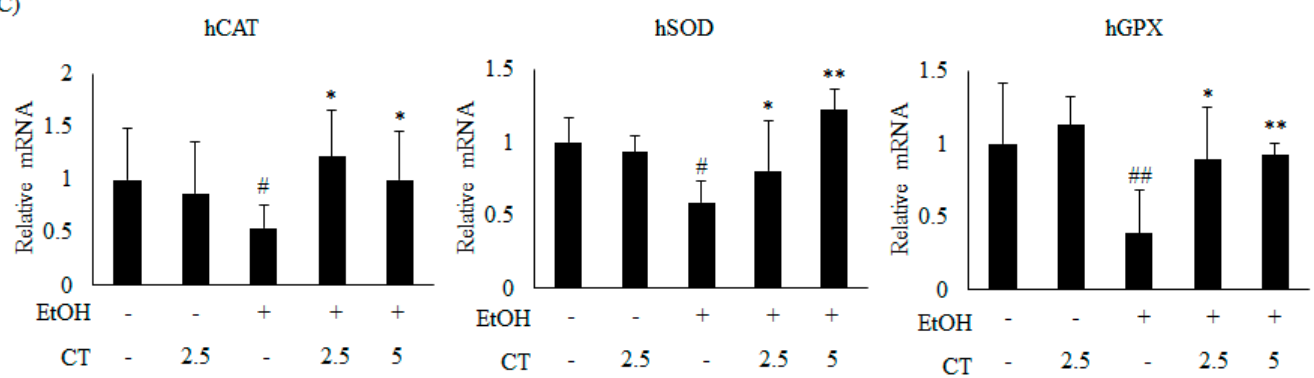

Figure 7. CT inhibited ethanol-induced oxidative stress in HepG2 cells. HepG2 cells were incubated with $50 \mathrm{mM}$ ethanol and treated with CT $(2.5$ or $5 \mu \mathrm{M})$ for $24 \mathrm{~h}$. (A) qPCR analysis of CYP2E1. (B) Measurement of intracellular GSH levels. (C) qPCR analysis of hCAT, hSOD, and hGPX. Data are shown as mean \pm SD from triplicate experiments. ${ }^{\#} p<0.05,{ }^{\# \#} p<0.01$ vs. untreated control, ${ }^{*} p<0.05$, ** $p<0.01$ vs. ethanol-treated group.

Moreover, AMPK/SIRT1 can regulate transcription factor Nrf2, which is an important modulator of the antioxidant defense response to oxidative stress by upregulating antioxidant genes expression [39,40,42]. Thus, we investigated whether Nrf2 is also involved in the protective effects of CT against oxidative stress. CT treatment increased the Nrf2 levels in a time dependent manner in HepG2 cells (Figure 5B). Afterwards, we further assessed the expression of Nrf2 in ethanol-fed mice and HepG2 or AML-12 cells. The Nrf2 protein levels were markedly decreased in both ethanol-fed mice (Figure 5C) and ethanol-treated HepG2 (Figure 5D) or AML12 cells (Figure 5E) as compared to the control groups, but CT treatment significantly reversed these effects. These findings suggest that the upregulation of Nrf2 may be also involved in CT-mediated safeguard against ethanol-induced oxidative stress. Furthermore, to investigate whether AMPK plays a role in CT-induced Nrf2 expression, we examined Nrf2 expression in CT-incubated HepG2 cells that were pretreated with compound C. Pretreatment with compound C efficiently blocked the CT-induced increase in the Nrf2 protein level (Supplementary Figure S4), which suggested that $A M P K$ activation is involved in the CT-induced activation of Nrf2.

\subsection{CT Prevents Ethanol-Induced Inflammation in Chronic Ethanol-Fed Mice and HepG2 Cells}

Next, we analyzed the effect of CT on inflammation in ethanol-fed mice and HepG2 cells. Ethanol exposure increased the mRNA levels of inflammatory genes, including tumor necrosis factor $\alpha(\mathrm{TNF} \alpha)$, interleukin 6 (IL-6), and monocyte chemoattractant protein 1 (MCP1), but CT significantly inhibited the ethanol-induced those inflammatory genes, which suggested that CT exerts anti-inflammatory effects in ethanol-fed mice and HepG2 cells, as shown in Figure 8A,B. Further, ethanol exposure reduced the level of $N F-\kappa B$ inhibitory protein (IкB), while increasing the level of p65, a subunit of $N F-\kappa B$ (Figure $8 C$ ). However, $C T$ treatment reversed both of these effects. These results indicate that $\mathrm{CT}$ inhibits ethanol-induced inflammation in HepG2 cells. These findings suggest that CT ameliorates ethanol-stimulated inflammation in ethanol-fed mice and HepG2 cells. 
A)
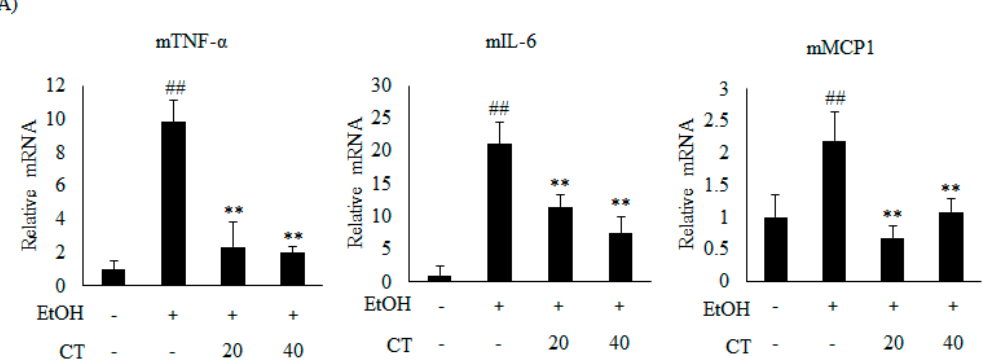

C)
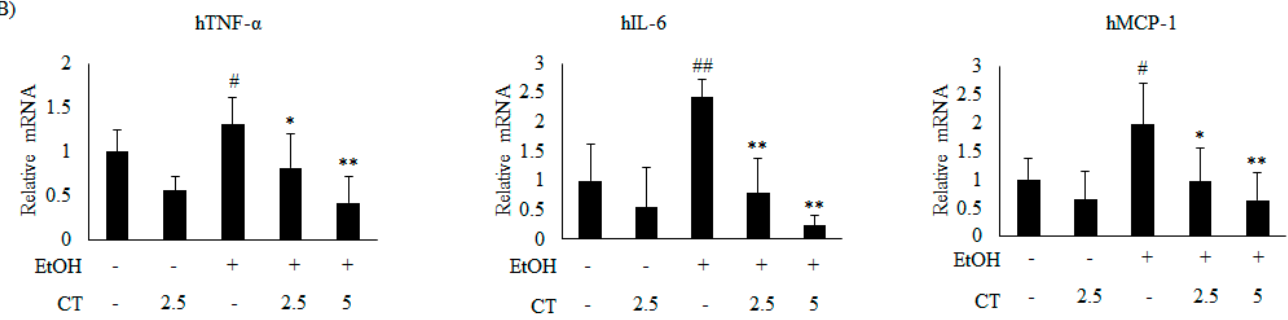

Figure 8. CT inhibited inflammation induced by ethanol in chronic ethanol-fed mice and HepG2 cells. (A) $\mathrm{qPCR}$ analysis of $\mathrm{mTNF}-\alpha, \mathrm{m} L \mathrm{~L}-6$, and $\mathrm{mMCP}-1$. Data are shown as mean $\pm \mathrm{SD}(\mathrm{n}=6) .{ }^{\# \#} p<0.01$ vs. pair-fed control mice, ${ }^{*} p<0.05,{ }^{* *} p<0.01$ vs. ethanol-fed mice. (B) qPCR analysis of hTNF- $\alpha$, $\mathrm{h} I L-6$, and $\mathrm{hMCP}-1$. Data are expressed as mean $\pm \mathrm{SD}$ from three independent experiments. ${ }^{\#} p<0.05$, \#\# $p<0.01$ vs. untreated control, ${ }^{*} p<0.05,{ }^{* *} p<0.01$ vs. ethanol-treated group. (C) HepG2 cells were incubated with $50 \mathrm{mM}$ ethanol and treated with CT $(2.5$ or $5 \mu \mathrm{M})$ for $24 \mathrm{~h}$. Western blot analysis of $I \kappa B$ and $N F-\kappa B$ p 65 . Densitometric analysis of western blots is given in Supplementary Figure S5.

\section{Discussion}

There are currently no approved therapies to treat non-alcoholic fatty liver disease, as well as alcoholic fatty liver disease. Herbal medicines have garnered significant attention in recent times, as they have very few side effects. Hence, we examined the protective effects of $\mathrm{CT}$ against chronic ethanol-induced fatty liver in vivo while using mice as well as in vitro using HepG2 cells. The results revealed that CT attenuates ethanol-induced hepatic injury via the inhibition of lipogenesis-related genes, oxidative stress, and inflammation.

In this present study, we first investigated whether CT attenuated ethanol-induced liver injuries in ethanol fed mice. The results revealed that the TG levels were elevated in the serum of chronic ethanol-fed mice, and the elevated TG levels were effectively decreased by CT treatment. Unexpectedly, the levels of AST and ALT were not significantly induced by only ethanol consumption, but CT administration decreased the levels compared to only ethanol-treated control group. Following oral ingestion, ethanol is oxidized to acetaldehyde by alcohol dehydrogenase (ADH) prior to further oxidization into acetate by aldehyde dehydrogenase (ALDH) [44]. Acetaldehyde, which is a major by-product of ethanol, is one of the predominant compounds that are highly toxic to hepatocytes. ALDH2 is a key enzyme for acetaldehyde detoxification in the liver [45]. Moreover, ALDH2 deficiency is associated with increased acetaldehyde and glucocorticoids after alcohol consumption [45]. We measured ADH1 and ALDH2 expression in mouse livers while using qPCR. The results revealed that ADH1 mRNA increased in mice treated with ethanol only and in mice treated with ethanol plus CT (Supplementary Figure S1D). However, ALDH2 expression also significantly increased in the CT treatment groups (Supplementary Figure S1E). These findings suggest that oxidation of ethanol to acetaldehyde and ALDH2 overexpression may detoxify acetaldehyde in the liver of CT-treated mice. In addition, hepatic TG levels were significantly elevated in the liver of chronic ethanol-fed mice and these elevated TG levels were effectively decreased by CT treatment. These findings indicated that CT prevents ethanol-induced lipid accumulation in the liver of ethanol fed mice. 
As mentioned earlier, there are multiple mechanisms that are associated with the development of alcoholic fatty liver [12,15]. Alcohol exposure is known to enhance lipogenesis by the upregulation of SREBP-1C and its target lipogenesis-related genes, including FAS, SCD1, and ACC, which leads to hepatic steatosis $[46,47]$. Meanwhile, alcohol-induced impairment of fatty acid oxidation via the inhibition of $P P A R \alpha$, which controls the expression of $C P T 1$ and $A C O$, also plays a pivotal role in the progresssion of hepatic steatosis [12,43]. Evidence suggests that the activation of $A M P K$ increases fatty acid oxidation and decreases lipogenesis [15,18-20]. As previously mentioned, AMPK/SIRT1 activation is a potential therapeutic target against ALD [22-24]. Hence, we evaluated the levels of phosphorylated $A M P K$ and SIRT1 protein in CT-treated HepG2 cells. Of note, CT treatment significantly increased the phosphorylated form of AMPK and ACC, a target of AMPK downstream, and the SIRT1 protein in a time dependent manner in HepG2 cells. It has been reported that the activation of AMPK plays an essential role in the protection of hepatic steatosis by suppressing ACC activity via phosphorylation for the inhibitory effect of fatty acid synthesis, and inhibiting both the transcriptional activity and the expression of $S R E B P-1 C$ and its target lipogenesis genes. In the present study, we observed that CT efficiently increased the phosphorylated ACC and down-regulated the expression of SREBP-1c and its target lipogenesis genes including FAS, SCD1, and ACC in ethanol-fed mice and ethanol-treated HepG2 cells. In addition, CT treatment significantly inhibited hepatic TG accumulation, which was consistent with the suppression of lipogenesis-related genes and the increased expression of fatty acid oxidation-related genes, such as PPAR $\alpha, C P T 1$, and ACO. Additionally, CT-treatment restored ethanol-reduced the levels of phosphorylated $A M P K$ and SIRT1 protein in the liver of ethanol-fed mice and HepG2 cells. Interestingly, compound C ( $A M P K$ Inhibitor) significantly inhibited ethanol-induced intracellular TG accumulation in HepG2 cells. However, co-treatment with compound C significantly blocked the CT-mediated reduction in TG accumulation, but not Ex52735 (SIRT1 inhibitor), which suggested that $A M P K$, as an upstream of SIRT1, mediates CT-induced protection against ethanol-promoted hepatic steatosis. Based on these results, CT-mediated-AMPK/SIRT1 activation might play a critical role in the protective effects of $\mathrm{CT}$ against alcoholic fatty liver.

CYP2E1 is a major culprit to ROS-generation-mediated fatty liver formation [29-31]. The elevation of lipid peroxidation has been reported in both acute and chronic ethanol-fed mouse models [48,49]. In addition, GSH is an important intracellular antioxidant enzyme that plays a pivotal role in antioxidant defense and detoxification [50]. Ethanol is also involved in the disruption of antioxidant activity, via the depletion of GSH levels and creation of favorable conditions for oxidative stress [51]. In the present study, ethanol increased the expression of CYP2E1 and TBARS, while reducing the hepatic GSH levels as well as antioxidant genes, such as CAT, SOD, and GPX. However, CT treatment significantly inhibited TBARS, and it led to a recovery of GSH levels and the antioxidant genes, suggesting that CT has antioxidant activity, which might be involved in the prevention of ALD.

Moreover, AMPK and SIRT1 can regulate transcription factors, such as Nrf2 and NF- $k B$, which are involved in regulating antioxidant genes against oxidative damage and the suppression of pro-inflammatory cytokines, respectively $[39,40,42]$. Nrf2, which is an essential transcription factor for expression of antioxidant genes, is another important modulator of the intracellular adaptive antioxidant response to oxidative stress [33,34]. Nrf2 binds to specific DNA sequence antioxidant responsive element (ARE) and stimulates the transcription of downstream target genes, antioxidant genes, including CAT, SOD, and GPX. In the current study, Nrf2 proteins were significantly decreased in ethanol-fed mice and ethanol-treated HepG2 cells, but these effects were significantly reversed in the CT-treated groups, which is consistent with upregulation of antioxidants genes, such including CAT, SOD, and GPX, suggesting that Nrf2 might play a role in CT-mediated antioxidant activity. Importantly, the inhibition of $A M P K$ using compound C prevented the CT-induced increase in Nrf2 protein, indicating that $A M P K$ activation is involved in CT-induced activation of Nrf2. Taken together, these results suggest that $A M P K / S I R T 1$ and Nrf2 signaling may be also involved in the protective effects of CT against ethanol-mediated oxidative stress. 
The increased expression of hepatic cytokines mediates the progression of alcoholic hepatic steatosis in ethanol-fed mice model [52]. Previous studies suggest that cytokines, such as interleukins and TNF- $\alpha$, play important roles in acute and chronic inflammation [12]. The key transcription factor, NF- $\kappa B$, stimulates inflammatory genes, such as TNF- $\alpha$, IL-6, and MCP-1. In our study, $C T$ reversed the ethanol-induced increase in the NF- $\kappa B$ p 65 protein level, and restored the I $\kappa B$ level. Consistent with the above results, CT significantly inhibited the ethanol-induced inflammatory genes, such as TNF- $\alpha$, IL-6, and MCP-1 at mRNA levels. Similar to these findings, cryptotanshinone demonstrated anti-inflammatory properties by inhibiting the expression of NO, iNOS, and COX-2 in RAW 264.7 cells [8]. These results revealed that CT has anti-inflammatory properties, which might help to prevent the progression of alcoholic hepatic steatosis.

In addition, previous study demonstrated that AMPK/SIRT activation inhibits the NF-kB-mediated inflammation pathway, which leads to repressing the expression of inflammatory cytokine genes [53]. In the current study, CT significantly blocked the ethanol-induced increase in NF- $\kappa B$ p 65 level by inducing the phosphorylation of $\mathrm{I} \mathrm{KB}$, and inhibited the expression of inflammatory cytokine gens, including TNF- $\alpha$, IL-6, and MCP-1, which suggested that AMPK/SIRT1 pathway might be also involved in the protective effects of $\mathrm{CT}$ against ethanol-mediated inflammation.

S. miltiorrhiza is popularly used for treating liver diseases, including hepatitis and cirrhosis, in many Asian countries. The previous study demonstrated that a standardized fraction from root of S. miltiorrhiza $(10 \mu \mathrm{g} / \mathrm{mL})$ and CT $(10 \mu \mathrm{M})$ suppressed alcohol-induced lipid accumulation and inhibited SREBP-1 in primary rat hepatocytes [10]. Moreover, tanshinone IIA $(10 \mu \mathrm{M})$ protected from lipopolysaccharides (LPS)—and ethanol-induced hepatotoxicity in RAW 264.7 cells [54]. It has also been showed that the purified extract of $S$. miltiorrhiza (PF2401-SF) protected against liver injury at $25-100 \mathrm{mg} / \mathrm{kg}$ in rats, which was more potent than the ethanol extract of S. miltiorrhiza. In our present study, a lower concentration of $\mathrm{CT}$ inhibited alcohol-induced steatosis, oxidative stress and inflammation in ethanol-fed mice ( 20 and $40 \mathrm{mg} / \mathrm{kg}$ ) and HepG2 cells $(5 \mu \mathrm{M})$. These findings suggest that $\mathrm{CT}$ is the major active component of $S$. miltiorrhiza inhibiting alcohol-induced liver injury.

\section{Conclusions}

In the present study, we have demonstrated that $\mathrm{CT}$ attenuates ethanol-induced hepatic steatosis via the inhibition of lipogenesis genes, oxidative stress, and inflammation for the first time in chronic ethanol-fed mice and HepG2 cells. The activation of AMPK/SIRT1, Nrf2, and inhibition of CYP2E1 might be involved in the protective effects of CT against ALD (Figure 9). The findings of this study suggest that CT could be an effective therapeutic agent for the treatment of ethanol-induced liver injury. 


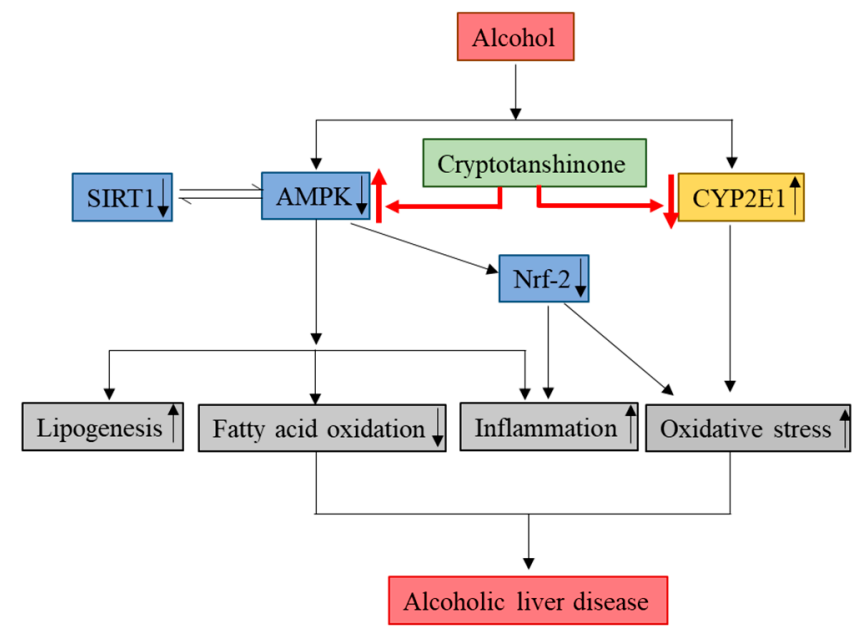

Figure 9. Molecular mechanisms involved in the protective effects of CT against ALD. Cryptotanshinone (CT) attenuates ethanol-induced hepatic steatosis, oxidative stress, and inflammation. The activation of $A M P K / S I R T 1$ and inhibition of CYP2E1 might be involved in hepatoprotective effects of CT against ethanol-induced liver. $\uparrow$ means upregulation and $\downarrow$ means downregulation.

\section{Materials and Methods}

\subsection{Reagents}

Cryptotanshinone ( $\geq 98 \%$ purity) was obtained from ChemFaces (Wuhan, China). Antibodies against SREBP-1c (H-160; sc-8984), PPAR $\alpha$ (H-2; sc-398394), IkB $\alpha$ (H-4; sc-164), NFkB p65 (F-6; sc-8008p65), AMPK $\alpha 1 / 2$ (D-6; sc-74461), SIRT1 (H-300; sc-15404), and $\beta$-actin (C4; sc-47778) were purchased from Santa Cruz Biotechnology (Santa Cruz, CA, USA). Specific primary antibodies against p-ACC (Ser79; \#3661s) and ACC (C83B10; \#3676s) were purchased from Cell Signaling Technology (Danvers, MA, USA). Antibodies against CYP2E1 (ab28146) and pAMPK $\alpha 1$ (Thr172; PA5-17831) were purchased from Abcam (Cambridge, MA, USA) and Invitrogen (Rockford, IL, USA), respectively. The Nrf2 antibody (NBP1-32822) was obtained from Novus Biologicals (Centennial, CO, USA). Ethanol, Ex52735, and compound C were obtained from Sigma (St. Louis, MO, USA).

\subsection{Cell Culture}

The human hepatocarcinoma cell line, HepG2, was obtained from American Type Culture Collection (Manassas, VA, USA) and grown in DMEM that was supplemented with $10 \%$ heat-inactivated FBS, penicillin (100 units $/ \mathrm{mL})$, and streptomycin sulfate $(100 \mu \mathrm{g} / \mathrm{mL})$. The murine cell line, AML-12 (non-cancerous), was obtained from Dr. SK Lee (Kyungpook National University, South Korea) and grown in DMEM/F12 medium supplemented with 10\% heat-inactivated FBS, penicillin (100 units/mL), and streptomycin sulfate $(100 \mu \mathrm{g} / \mathrm{mL}), 1 \times$ Insulin-Transferrin-Selenium (ITS-G) mixture, and $40 \mathrm{ng} / \mathrm{mL}$ dexamethasone. The cells were maintained at $37^{\circ} \mathrm{C}$ in an atmosphere of $5 \% \mathrm{CO}_{2}$.

\subsection{Cytotoxicity Assay}

The HepG2 and AML-12 cells were incubated with CT for $3 \mathrm{~h}$ and then treated with $50 \mathrm{mM}$ ethanol for $24 \mathrm{~h}$. The inhibitory effects of CT and ethanol on HepG2 and AML-12 cells were assessed while using a 3-(4,5-dimethylthiazol-2-yl)-2,5-diphenyltetrazolium bromide (MTT) assay, as per the manufacturer's instructions (Promega, Madison, WI, USA). 


\subsection{Animal Experiments}

Pusan National University's Institutional Animal Care and Use Committee approved all of the animal experiments, which were in accordance with the established ethical and scientific care procedures (PNU-2018-1969). Male C57BL/six mice (eight-week-old, 20-22 g) were obtained from Doo Yeol Biotech (Seoul, South Korea). The mice were maintained at $22 \pm 2{ }^{\circ} \mathrm{C}$ on a $12 \mathrm{~h}: 12 \mathrm{~h}$ light-dark cycle and $50-60 \%$ relative humidity. For the experiments, the mice were randomly divided into the following four groups ( $n=10 /$ group): control, ethanol, ethanol + CT $20 \mathrm{mg} / \mathrm{kg}$, and ethanol + CT $40 \mathrm{mg} / \mathrm{kg}$. A model of chronic EtOH intake was used for feeding, according to a previously described NIAAA protocol [55]. The mice were given free access to the control diet or alcohol LiebereDeCarli liquid diet (Research Diets Inc., NJ, USA) for four weeks, and from third week onwards, CT ( $20 \mathrm{mg} / \mathrm{kg}$ or $40 \mathrm{mg} / \mathrm{kg}$ ) was orally administered daily. After four weeks, the mice were euthanized, following which their blood and liver tissue were stored at $-80{ }^{\circ} \mathrm{C}$ until further analyses.

\subsection{TG Measurement}

The TG levels of liver tissue lysates or HepG2 cells and AML-12 cells were measured, as described previously [56]. Briefly, TG were extracted while using chloroform/methanol (2:1), evaporated, and then dissolved in ethanol. TG content was determined while using an enzyme reaction kit (Asan Pharmaceutical, Seoul, Korea). The TG levels were normalized to the protein concentration.

\subsection{Histopathological Analysis}

Samples from the liver were separated, fixed in $10 \%$ buffered formalin and then embedded in paraffin, and sectioned (5 $\mu \mathrm{m}$ thickness) while using a frozen microtome (HM560H, Microm International, Walldorf, Germany). Subsequently, the sectioned tissues were stained with hematoxylin and eosin (H\&E) and Oil Red O (ORO), following which, they were observed under a light microscope. The quantification of H\&E staining based on steatosis, inflammation, and fibrosis was undertaken by NAFLD activity score (NAS) from the Nonalcoholic steatohepatitis-Clinical Research Network (NASH-CRN), as previously described [57].

\subsection{Biochemical Analysis}

ALT, AST, and TG levels of serum samples were determined while using FUJI DRI-CHEM 7000i (FUJI FILM, Tokyo, Japan).

\subsection{Quantitative Polymerase Chain Reaction ( $q P C R$ )}

The total RNA was extracted from mice liver or HepG2 cells while using TRIzol ${ }^{\mathrm{TM}}$ (Invitrogen, Carlsbad, CA, USA), according to the manufacturer's instructions. The isolated RNA $(1 \mu \mathrm{g})$ was converted in to cDNA using TOPScript RT DryMix (Enzynomics, Daejeon, Korea). Quantitative real-time PCR was analyzed using a SYBR Green premixed Taq reaction mixture with the gene-specific primers listed in Supplementary Table S1. The geometric mean of housekeeping gene $18 \mathrm{~S}$ ribosomal RNA (18S rRNA) was used as an internal control to normalize the variability in expression levels. The expression levels were analyzed using the $2-\Delta \Delta C$ T method. as described previously [58].

\subsection{Measurement of Hepatic Lipid Peroxidation and GSH Level}

Hepatic lipid peroxidation was measured while using an OxiSelect ${ }^{\mathrm{TM}}$ TBARS assay kit-MDA Quantitation (Cell Biolabs Inc., San Diego, CA, USA). The GSH level in the liver was assessed using a kit (K261-100, BioVision, CA, USA). All of the measurements were carried out according to the manufacturers' instructions. 


\subsection{Western Blot Analysis}

The protein lysates were prepared from mice liver or HepG2 and AML-12 cells using Pro-Prep Protein Extraction Solution (Intron Biotechnology, Seoul, Korea), according to the manufacturer's instructions. Equal amounts of protein $(50 \mu \mathrm{g})$ were separated by $12 \%$ SDS-PAGE and then transferred to polyvinylidene difluoride membranes (Amersham Pharmacia Biotech, Amersham, UK). After transfer, the membranes were blocked in 5\% nonfat skim milk, followed by incubation with primary antibodies (1:1000) overnight at $4{ }^{\circ} \mathrm{C}$. After over night incubation, membranes were probed with anti-rabbit or anti-mouse secondary antibodies (1:1000) (Santa Cruz Biotechnology) conjugated to peroxidase, and the protein bands were detected by using an enhanced chemiluminescence system (ECL Advance, GE Healthcare, Hatfield, UK).

\subsection{Statistical Analysis}

The data that are shown in this study are expressed as mean $\pm \mathrm{SD}$. The data were analyzed while using one-way ANOVA, and the differences between means were determined using the Tukey-Kramer post-hoc test. The sample size was calculated by assuming the effect size and the variance for NAS of pair-fed control and ethanol-fed mice based on literature data. The values were considered statistically significant at $p<0.05$.

Supplementary Materials: Supplementary materials can be found at http://www.mdpi.com/1422-0067/21/1/265/s1.

Author Contributions: A.N. and M.H.J. conceptualized the study. A.N., J.-H.K. conducted the experiment. A.N., J.-H.K. and D.Y.J. analyzed the data. A.N. and M.H.J. wrote the manuscript. All authors have read and agreed to the published version of the manuscript.

Funding: This study was financially supported by the [2018 Post-Doc. Development Program] of Pusan National University and the National Research Foundation of Korea (NRF) grant funded by the Korean government (MSIP) (No. 2014R1A5A2009936).

Acknowledgments: We thank Lee, S.K. (Kyungpook National University, Korea) for providing AML-12 cells.

Conflicts of Interest: The authors declare no conflict of interest.

\section{Abbreviations}

$\begin{array}{ll}\text { ACC } & \text { Acetyl-CoA carboxylase } \\ \text { ACO } & \text { Acyl-coenzyme A oxidase } \\ \text { ALD } & \text { Alcoholic liver disease } \\ \text { ALT } & \text { Alanine aminotransferase } \\ \text { AMPK } & \text { AMP-activated protein kinase } \\ \text { AST } & \text { Aspartate aminotransferase } \\ \text { CYP2E1 } & \text { Cytochrome P450 2E1 } \\ \text { CPT1 } \alpha & \text { Carnitine palmitoyltransferase-1 } \alpha \\ \text { CAT } & \text { Catalase } \\ \text { CT } & \text { Cryptotanshinone } \\ \text { EtoH } & \text { Ethanol } \\ \text { FAS } & \text { Fatty acid synthase } \\ \text { GPX } & \text { Glutathione peroxidase } \\ \text { GSH } & \text { Glutathione } \\ \text { H\&E } & \text { Haematoxylin and eosin } \\ \text { IKB } & \text { I Kappa B-alpha } \\ \text { IL6 } & \text { Interleukin 6 } \\ \text { MCP-1 } & \text { Monocyte chemotactic protein-1 } \\ \text { NF- } \text { B } & \text { Nuclear factor-kappa B } \\ \text { NRF2 } & \text { Nuclear factor erythroid-derived 2-related factor 2 } \\ \text { ORO } & \text { Oil Red O } \\ \text { PPAR } \alpha & \text { Peroxisome proliferator-activated receptor } \alpha \\ \end{array}$




$\begin{array}{ll}\text { qPCR } & \text { Quantitative polymerase chain reaction } \\ \text { ROS } & \text { Reactive oxygen species } \\ \text { SCD1 } & \text { Stearoyl-CoA desaturase-1 } \\ \text { SIRT1 } & \text { Sirtuin 1 } \\ \text { SOD } & \text { Superoxide dismutase } \\ \text { SREBP-1c } & \text { Sterol regulatory element-binding protein-1c } \\ \text { TBARS } & \text { Thiobarbituric acid reactive substances } \\ \text { TG } & \text { Triglyceride } \\ \text { TNF } \alpha & \text { Tumor necrosis factor- } \alpha\end{array}$

\section{References}

1. Lei, X.L.; Chiou, G.C. Studies on cardiovascular actions of Salvia miltiorrhiza. Am. J. Chin. Med. 1986, 14, $26-32$. [CrossRef] [PubMed]

2. Wang, N.; Luo, H.W.; Niwa, M.; Ji, J. A new platelet aggregation inhibitor from Salvia miltiorrhiza. Planta Med. 1989, 55, 390-391. [CrossRef] [PubMed]

3. Xiong, Z.B.; Wu, P.; Huang, Y.F. Protective mechanisms of radix salviae miltiorrhizae against chronic alcoholic liver injury in mice. Zhongguo Zhong Xi Yi Jie He Za Zhi 2005, 25, 425-428. [PubMed]

4. Brunetti, G.; Serra, S.; Vacca, G.; Lobina, C.; Morazzoni, P.; Bombardelli, E.; Colombo, G.; Gessa, G.L.; Carai, M.A. IDN 5082, a standardized extract of Salvia miltiorrhiza, delays acquisition of alcohol drinking behavior in rats. J. Ethnopharmacol. 2003, 85, 93-97. [CrossRef]

5. Peng, Y.; Yang, T.; Huang, K.; Shen, L.; Tao, Y.; Liu, C. Salvia Miltiorrhiza Ameliorates Liver Fibrosis by Activating Hepatic Natural Killer Cells in Vivo and in Vitro. Front. Pharmacol. 2018, 9, 762. [CrossRef]

6. Cao, E.H.; Liu, X.Q.; Wang, J.J.; Xu, N.F. Effect of natural antioxidant tanshinone II-A on DNA damage by lipid peroxidation in liver cells. Free Radic. Biol. Med. 1996, 20, 801-806. [CrossRef]

7. Park, E.J.; Zhao, Y.Z.; Kim, Y.C.; Sohn, D.H. PF2401-SF, standardized fraction of Salvia miltiorrhiza and its constituents, tanshinone I, tanshinone IIA, and cryptotanshinone, protect primary cultured rat hepatocytes from bile acid-induced apoptosis by inhibiting JNK phosphorylation. Food Chem. Toxicol 2007, 45, 1891-1898. [CrossRef]

8. Li, X.; Lian, L.H.; Bai, T.; Wu, Y.L.; Wan, Y.; Xie, W.X.; Jin, X.; Nan, J.X. Cryptotanshinone inhibits LPS-induced proinflammatory mediators via TLR4 and TAK1 signaling pathway. Int. Immunopharmacol. 2011, 11, 1871-1876. [CrossRef]

9. Tang, S.; Shen, X.Y.; Huang, H.Q.; Xu, S.W.; Yu, Y.; Zhou, C.H.; Chen, S.R.; Le, K.; Wang, Y.H.; Liu, P.Q. Cryptotanshinone suppressed inflammatory cytokines secretion in RAW264.7 macrophages through inhibition of the NF-kappaB and MAPK signaling pathways. Inflammation 2011, 34, 111-118. [CrossRef]

10. Yin, H.Q.; Choi, Y.J.; Kim, Y.C.; Sohn, D.H.; Ryu, S.Y.; Lee, B.H. Salvia miltiorrhiza Bunge and its active component cryptotanshinone protects primary cultured rat hepatocytes from acute ethanol-induced cytotoxicity and fatty infiltration. Food Chem. Toxicol. 2009, 47, 98-103. [CrossRef]

11. Mann, R.E.; Smart, R.G.; Govoni, R. The epidemiology of alcoholic liver disease. Alcohol Res. Health 2003, $27,209-219$. [PubMed]

12. Gao, B.; Bataller, R. Alcoholic liver disease: Pathogenesis and new therapeutic targets. Gastroenterology 2011, 141, 1572-1585. [CrossRef] [PubMed]

13. Kim, J.H.; Hwang, C.E.; Lee, C.K.; Lee, J.H.; Kim, G.M.; Jeong, S.H.; Shin, J.H.; Kim, J.S.; Cho, K.M. Characteristics and antioxidant effect of garlic in the fermentation of Cheonggukjang by Bacillus amyloliquefaciens MJ1-4. J. Microbiol. Biotechnol. 2014, 24, 959-968. [CrossRef] [PubMed]

14. Altamirano, J.; Bataller, R. Alcoholic liver disease: Pathogenesis and new targets for therapy. Nat. Rev. Gastroenterol. Hepatol. 2011, 8, 491-501. [CrossRef] [PubMed]

15. Tang, C.C.; Huang, H.P.; Lee, Y.J.; Tang, Y.H.; Wang, C.J. Hepatoprotective effect of mulberry water extracts on ethanol-induced liver injury via anti-inflammation and inhibition of lipogenesis in C57BL/6J mice. Food Chem. Toxicol. 2013, 62, 786-796. [CrossRef]

16. Hardie, D.G. Minireview: The AMP-activated protein kinase cascade: The key sensor of cellular energy status. Endocrinology 2003, 144, 5179-5183. [CrossRef] 
17. Carling, D. The AMP-activated protein kinase cascade-a unifying system for energy control. Trends Biochem. Sci. 2004, 29, 18-24. [CrossRef]

18. Steinberg, G.R.; Kemp, B.E. AMPK in Health and Disease. Physiol Rev. 2009, 89, 1025-1078. [CrossRef]

19. Rui, B.B.; Chen, H.; Jang, L.; Li, Z.; Yang, J.M.; Xu, W.P.; Wei, W. Melatonin Upregulates the Activity of AMPK and Attenuates Lipid Accumulation in Alcohol-induced Rats. Alcohol Alcohol. 2016, 51, 11-19. [CrossRef]

20. Tomita, K.; Tamiya, G.; Ando, S.; Kitamura, N.; Koizumi, H.; Kato, S.; Horie, Y.; Kaneko, T.; Azuma, T.; Nagata, H.; et al. AICAR, an AMPK activator, has protective effects on alcohol-induced fatty liver in rats. Alcohol Clin. Exp. Res. 2005, 29, 240S-245S. [CrossRef]

21. Canto, C.; Auwerx, J. PGC-1alpha, SIRT1 and AMPK, an energy sensing network that controls energy expenditure. Curr. Opin. Lipidol. 2009, 20, 98-105. [CrossRef] [PubMed]

22. Lan, F.; Cacicedo, J.M.; Ruderman, N.; Ido, Y. SIRT1 modulation of the acetylation status, cytosolic localization, and activity of LKB1. Possible role in AMP-activated protein kinase activation. J. Biol. Chem. 2008, 283, 27628-27635. [CrossRef] [PubMed]

23. Hou, X.; Xu, S.; Maitland-Toolan, K.A.; Sato, K.; Jiang, B.; Ido, Y.; Lan, F.; Walsh, K.; Wierzbicki, M.; Verbeuren, T.J.; et al. SIRT1 regulates hepatocyte lipid metabolism through activating AMP-activated protein kinase. J. Biol. Chem. 2008, 283, 20015-20026. [CrossRef] [PubMed]

24. You, M.; Jogasuria, A.; Taylor, C.; Wu, J. Sirtuin 1 signaling and alcoholic fatty liver disease. Hepatobiliary Surg. Nutr. 2015, 4, 88-100. [CrossRef]

25. Nagappan, A.; Jung, D.Y.; Kim, J.H.; Lee, H.; Jung, M.H. Gomisin N Alleviates Ethanol-Induced Liver Injury through Ameliorating Lipid Metabolism and Oxidative Stress. Int. J. Mol. Sci. 2018, 19, 2601. [CrossRef]

26. Cederbaum, A.I.; Wu, D.; Mari, M.; Bai, J. CYP2E1-dependent toxicity and oxidative stress in HepG2 cells. Free Radic. Biol. Med. 2001, 31, 1539-1543. [CrossRef]

27. Cederbaum, A.I. Introduction-serial review: Alcohol, oxidative stress and cell injury. Free Radic. Biol. Med. 2001, 31, 1524-1526. [CrossRef]

28. Arteel, G.E. Oxidants and antioxidants in alcohol-induced liver disease. Gastroenterology 2003, 124, 778-790. [CrossRef]

29. Caro, A.A.; Cederbaum, A.I. Oxidative stress, toxicology, and pharmacology of CYP2E1. Annu. Rev. Pharmacol. Toxicol. 2004, 44, 27-42. [CrossRef]

30. Butura, A.; Nilsson, K.; Morgan, K.; Morgan, T.R.; French, S.W.; Johansson, I.; Schuppe-Koistinen, I.; Ingelman-Sundberg, M. The impact of CYP2E1 on the development of alcoholic liver disease as studied in a transgenic mouse model. J. Hepatol. 2009, 50, 572-583. [CrossRef]

31. Lu, Y.; Zhuge, J.; Wang, X.; Bai, J.; Cederbaum, A.I. Cytochrome P450 2E1 contributes to ethanol-induced fatty liver in mice. Hepatology 2008, 47, 1483-1494. [CrossRef] [PubMed]

32. Morimoto, M.; Hagbjork, A.L.; Wan, Y.J.; Fu, P.C.; Clot, P.; Albano, E.; Ingelman-Sundberg, M.; French, S.W. Modulation of experimental alcohol-induced liver disease by cytochrome P450 2E1 inhibitors. Hepatology 1995, 21, 1610-1617. [PubMed]

33. Hou, D.X.; Korenori, Y.; Tanigawa, S.; Yamada-Kato, T.; Nagai, M.; He, X.; He, J. Dynamics of Nrf2 and Keap1 in ARE-mediated NQO1 expression by wasabi 6-(methylsulfinyl)hexyl isothiocyanate. J. Agric. Food Chem. 2011, 59, 11975-11982. [CrossRef] [PubMed]

34. Xue, D.; Zhou, C.; Shi, Y.; Lu, H.; Xu, R.; He, X. Nuclear transcription factor Nrf2 suppresses prostate cancer cells growth and migration through upregulating ferroportin. Oncotarget 2016, 7, 78804-78812. [CrossRef] [PubMed]

35. Cao, H.; Chen, B.; Deng, Y.; Lu, X.; Yu, G. Baicalin increases the antioxidant capacity via promoting the nuclear translocation of NF-E2-related factor 2 (Nrf2) in N2a/APPswe cells. Xi Bao Yu Fen Zi Mian Yi Xue Za Zhi 2015, 31, 1597-1601. [PubMed]

36. Lamle, J.; Marhenke, S.; Borlak, J.; von Wasielewski, R.; Eriksson, C.J.; Geffers, R.; Manns, M.P.; Yamamoto, M.; Vogel, A. Nuclear factor-eythroid 2-related factor 2 prevents alcohol-induced fulminant liver injury. Gastroenterology 2008, 134, 1159-1168. [CrossRef]

37. Wu, K.C.; Liu, J.; Klaassen, C.D. Role of Nrf2 in preventing ethanol-induced oxidative stress and lipid accumulation. Toxicol. Appl. Pharmacol. 2012, 262, 321-329. [CrossRef]

38. Gu, L.; Tao, X.; Xu, Y.; Han, X.; Qi, Y.; Xu, L.; Yin, L.; Peng, J. Dioscin alleviates BDL- and DMN-induced hepatic fibrosis via Sirt1/Nrf2-mediated inhibition of p38 MAPK pathway. Toxicol. Appl. Pharmacol. 2016, 292, 19-29. [CrossRef] 
39. Tang, L.; Chen, Q.; Meng, Z.; Sun, L.; Zhu, L.; Liu, J.; Hu, J.; Ni, Z.; Wang, X. Suppression of Sirtuin-1 Increases IL-6 Expression by Activation of the Akt Pathway During Allergic Asthma. Cell. Physiol. Biochem. 2017, 43, 1950-1960. [CrossRef]

40. Meng, X.; Tan, J.; Li, M.; Song, S.; Miao, Y.; Zhang, Q. Sirt1: Role Under the Condition of Ischemia/Hypoxia. Cell. Mol. Neurobiol. 2017, 37, 17-28. [CrossRef]

41. Price, N.L.; Gomes, A.P.; Ling, A.J.; Duarte, F.V.; Martin-Montalvo, A.; North, B.J.; Agarwal, B.; Ye, L.; Ramadori, G.; Teodoro, J.S.; et al. SIRT1 is required for AMPK activation and the beneficial effects of resveratrol on mitochondrial function. Cell Metab. 2012, 15, 675-690. [CrossRef] [PubMed]

42. Takada, Y.; Singh, S.; Aggarwal, B.B. Identification of a p65 peptide that selectively inhibits NF-kappa B activation induced by various inflammatory stimuli and its role in down-regulation of NF-kappaB-mediated gene expression and up-regulation of apoptosis. J. Biol. Chem. 2004, 279, 15096-15104. [CrossRef] [PubMed]

43. Kong, L.; Ren, W.; Li, W.; Zhao, S.; Mi, H.; Wang, R.; Zhang, Y.; Wu, W.; Nan, Y.; Yu, J. Activation of peroxisome proliferator activated receptor alpha ameliorates ethanol induced steatohepatitis in mice. Lipids Health Dis. 2011, 10, 246. [CrossRef] [PubMed]

44. Zakhari, S. Overview: How is alcohol metabolized by the body? Alcohol Res. Health 2006, 29, $245-254$.

45. Gao, Y.; Zhou, Z.; Ren, T.; Kim, S.J.; He, Y.; Seo, W.; Guillot, A.; Ding, Y.; Wu, R.; Shao, S.; et al. Alcohol inhibits T-cell glucose metabolism and hepatitis in ALDH2-deficient mice and humans: Roles of acetaldehyde and glucocorticoids. Gut 2019, 68, 1311-1322. [CrossRef]

46. You, M.; Fischer, M.; Deeg, M.A.; Crabb, D.W. Ethanol induces fatty acid synthesis pathways by activation of sterol regulatory element-binding protein (SREBP). J. Biol. Chem. 2002, 277, 29342-29347. [CrossRef]

47. Ji, C.; Kaplowitz, N. Betaine decreases hyperhomocysteinemia, endoplasmic reticulum stress, and liver injury in alcohol-fed mice. Gastroenterology 2003, 124, 1488-1499. [CrossRef]

48. Khanal, T.; Choi, J.H.; Hwang, Y.P.; Chung, Y.C.; Jeong, H.G. Protective effects of saponins from the root of Platycodon grandiflorum against fatty liver in chronic ethanol feeding via the activation of AMP-dependent protein kinase. Food Chem. Toxicol. 2009, 47, 2749-2754. [CrossRef]

49. Kim, S.J.; Lee, J.W.; Jung, Y.S.; Kwon, D.Y.; Park, H.K.; Ryu, C.S.; Kim, S.K.; Oh, G.T.; Kim, Y.C. Ethanol-induced liver injury and changes in sulfur amino acid metabolomics in glutathione peroxidase and catalase double knockout mice. J. Hepatol. 2009, 50, 1184-1191. [CrossRef]

50. Dickinson, D.A.; Forman, H.J. Cellular glutathione and thiols metabolism. Biochem. Pharmacol. 2002, 64, $1019-1026$. [CrossRef]

51. Das, S.K.; Vasudevan, D.M. Alcohol-induced oxidative stress. Life Sci. 2007, 81, 177-187. [CrossRef] [PubMed]

52. Huang, L.L.; Wan, J.B.; Wang, B.; He, C.W.; Ma, H.; Li, T.W.; Kang, J.X. Suppression of acute ethanol-induced hepatic steatosis by docosahexaenoic acid is associated with downregulation of stearoyl-CoA desaturase 1 and inflammatory cytokines. Prostaglandins Leukot. Essent. Fatty Acids 2013, 88, 347-353. [CrossRef] [PubMed]

53. Tian, R.; Yang, W.; Xue, Q.; Gao, L.; Huo, J.; Ren, D.; Chen, X. Rutin ameliorates diabetic neuropathy by lowering plasma glucose and decreasing oxidative stress via Nrf2 signaling pathway in rats. Eur. J. Pharmacol. 2016, 771, 84-92. [CrossRef] [PubMed]

54. Yin, H.Q.; Kim, Y.S.; Choi, Y.J.; Kim, Y.C.; Sohn, D.H.; Ryu, S.Y.; Lee, B.H. Effects of tanshinone IIA on the hepatotoxicity and gene expression involved in alcoholic liver disease. Arch. Pharm. Res. 2008, 31, 659-665. [CrossRef] [PubMed]

55. Bertola, A.; Mathews, S.; Ki, S.H.; Wang, H.; Gao, B. Mouse model of chronic and binge ethanol feeding (the NIAAA model). Nat. Protoc. 2013, 8, 627-637. [CrossRef] [PubMed]

56. Ki, S.H.; Park, O.; Zheng, M.; Morales-Ibanez, O.; Kolls, J.K.; Bataller, R.; Gao, B. Interleukin-22 treatment ameliorates alcoholic liver injury in a murine model of chronic-binge ethanol feeding: Role of signal transducer and activator of transcription 3. Hepatology 2010, 52, 1291-1300. [CrossRef] 
57. Kleiner, D.E.; Brunt, E.M.; Van Natta, M.; Behling, C.; Contos, M.J.; Cummings, O.W.; Ferrell, L.D.; Liu, Y.C.; Torbenson, M.S.; Unalp-Arida, A.; et al. Design and validation of a histological scoring system for nonalcoholic fatty liver disease. Hepatology 2005, 41, 1313-1321. [CrossRef]

58. Livak, K.J.; Schmittgen, T.D. Analysis of relative gene expression data using real-time quantitative PCR and the 2(-Delta Delta C(T)) Method. Methods 2001, 25, 402-408. [CrossRef]

(C) 2019 by the authors. Licensee MDPI, Basel, Switzerland. This article is an open access article distributed under the terms and conditions of the Creative Commons Attribution (CC BY) license (http://creativecommons.org/licenses/by/4.0/). 